\title{
Leches a base de plantas: Coco'
}

\section{Celia Andreo, Daniela Rivero-Mendoza y Wendy J Dahl²}

La leche de coco es una de las muchas variedades de alternativas vegetales a la leche de vaca. Las razones que pueden llevar a los consumidores hacia alternativas a la leche no láctea incluyen la adherencia a una dieta vegana, la intolerancia a la lactosa, la alergia a la leche de vaca o simplemente la preferencia (Sethi et al. 2016). El propósito de esta guía es informarle sobre el contenido de nutrientes de la leche de coco como bebida y sus posibles beneficios y riesgos para la salud.

\section{¿Cómo se elabora la leche de coco?}

La bebida de leche de coco contiene agua y crema de coco, una forma concentrada de leche de coco. Esta publicación es acerca de la leche de coco diluida que se vende como bebida y no acerca de la leche de coco concentrada que frecuentemente viene en la lata y se utiliza para cocinar. Otros ingredientes que se agregan a la leche de coco pueden incluir lecitina para emulsionar y gomas para espesar y textura (Patil et al. 2018, USDA n.d.). Además, se puede agregar sal para darle sabor. Algunas marcas de leche de coco están fortificadas con calcio y vitaminas A y D para proporcionar niveles de estos nutrientes similares a los de la leche de vaca (USDA n.d.). Se puede agregar vitamina B12 para proporcionar una fuente de este nutriente para las personas que consumen una dieta vegana.

La crema de coco se elabora a partir de la pulpa de coco prensada en seco. Luego, la crema de coco se diluye con agua para hacer una bebida de leche de coco. La leche de coco también se puede preparar empapando la pulpa de coco madura rallada en agua. Se hierbe para garantizar que el producto sea estable en almacenamiento (Patil et al. 2018). Tenga en cuenta que la leche de coco es bastante diferente al agua de coco. El agua de coco es un líquido dulce y translúcido que se puede consumir directamente del coco o como variedades envasadas comercialmente.

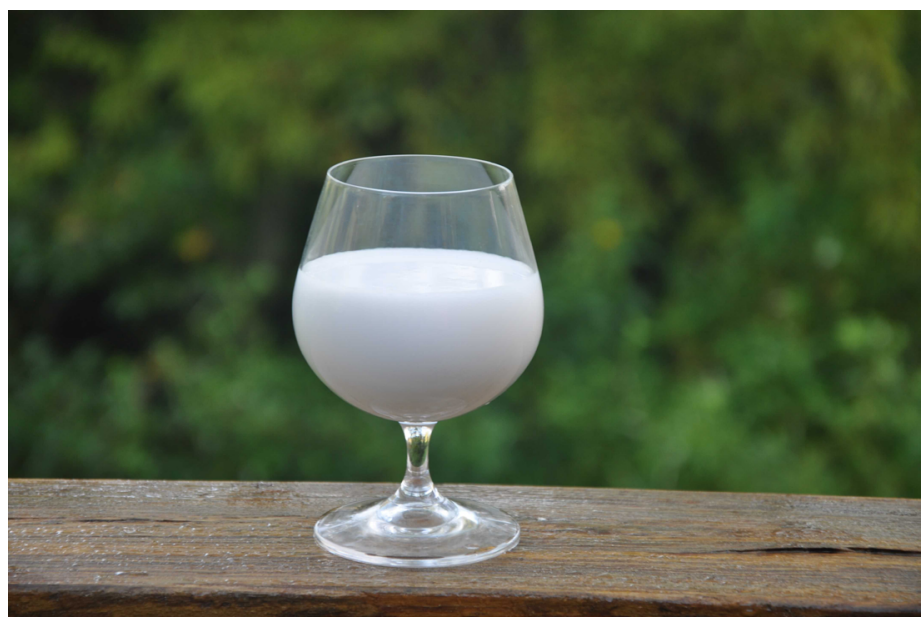

Crédito: Lincoln Zotarelli, UF/IFAS

\section{¿Cómo se compara el perfil de nutrientes de la leche de coco con el de la leche de vaca?}

Un punto importante a considerar al seleccionar una leche de origen vegetal es la composición nutricional. El contenido nutricional de la leche de coco es diferente al de la leche de vaca. La Tabla 1 muestra una comparación entre

1. Este documento, FSHN20-49s, es uno de una serie de publicaciones del Ciencia de los Alimentos y Nutrición Humana, Servicio de Extensión Cooperativa de la Florida, Instituto de Alimentos y Ciencias Agrícolas, Universidad de la Florida. (UF/IFAS). Fecha de primera publicación: noviembre 2020. Visite nuestro sitio web EDIS en https://edis.ifas.ufl.edu.

2. Celia Andreo, former MS-DI graduate student, Food Science and Human Nutrition Department; Daniela Rivero-Mendoza, Extension and research coordinator; and Wendy J Dahl, associate professor, Food Science and Human Nutrition Department; UF/IFAS Extension, Gainesville, FL 32611.

The Institute of Food and Agricultural Sciences (IFAS) is an Equal Opportunity Institution authorized to provide research, educational information and other services

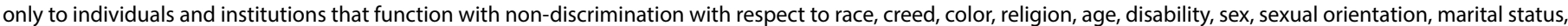

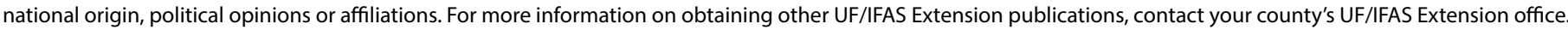
U.S. Department of Agriculture, UF/IFAS Extension Service, University of Florida, IFAS, Florida A \& M University Cooperative Extension Program, and Boards of County Commissioners Cooperating. Nick T. Place, dean for UF/IFAS Extension. 
la leche de coco sin azúcar y la leche de vaca sin grasa, baja en grasa y entera (USDA n.d.).

Calorías. Una taza de leche de coco sin azúcar contiene 40 calorías, que es menos que cualquier tipo de leche de vaca (USDA n.d.). Tenga en cuenta que el contenido calórico de la leche de coco sin azúcar, destinada a una bebida, es mucho más bajo que la leche de coco, a menudo enlatada, destinada a cocinar. La leche o crema de coco enlatada, que es mucho más concentrada, puede contener hasta 400 calorías por taza (USDA n.d.).

Proteínas. La leche de vaca es una fuente importante de proteínas, mientras que la leche de coco no proporciona proteínas (USDA n.d.).

Grasas. El contenido de grasa de la leche de coco sin azúcar es menor que el de la leche de vaca entera, pero es mayor que el de la leche de vaca descremada o baja en grasa. La grasa de la leche de coco es principalmente grasa saturada, más alta que la de la leche de vaca entera y baja en grasa (USDA n.d.).

Carbohidratos. La leche de vaca contiene aproximadamente $12 \mathrm{~g}$ de carbohidratos por porción, casi todos en forma de lactosa, un azúcar que está presente naturalmente en la leche (USDA n.d.). La leche de coco sin azúcar contiene solo $1 \mathrm{~g}$ de carbohidrato (Silk n.d.-a). Sin embargo, las variedades saborizadas de la leche de coco puede contener hasta $15 \mathrm{~g}$ de carbohidratos por porción, una parte significativa de los cuales son azúcares agregados (USDA n.d., Silk n.d.-b). Las pautas dietéticas para estadounidenses desalientan el consumo de azúcares añadidos, incluidos bebidas endulzadas con azúcar (USDA 2015). La leche de coco no es una fuente de fibra.

Vitaminas y Minerales. Tanto la leche de vaca como la de coco están fortificadas con vitaminas A y D, aunque los niveles pueden ser más altos en la leche de coco (Silk n.d.-b). La leche de coco también está fortificada con calcio, a un nivel más alto que la leche de vaca. La leche de coco puede estar fortificada con vitamina B12 a un nivel similar al de la leche de vaca. La leche de coco generalmente tiene menos sodio que la leche de vaca, pero los niveles de sodio pueden variar según el fabricante.

\section{¿Cuáles son los posibles beneficios para la salud de la leche de coco?}

Es importante considerar sus necesidades de alimentación antes de cambiar a la leche de coco. Un beneficio potencial de la leche de coco sin azúcar es el bajo contenido calórico.
Una persona que está controlando su ingesta calórica, con el propósito de perder peso, puede seleccionar la leche de coco sin azúcar porque proporciona menos calorías que la leche de vaca. Sin embargo, los consumidores deben conocer el tipo de leche de coco que compran. Algunas variedades de leche de coco pueden incluir cantidades significativas de azúcares añadidos y, por lo tanto, pueden proporcionar más calorías que la leche de vaca. La leche de vaca es una fuente importante de proteínas, así como de muchos otros nutrientes, en comparación con la leche de coco, que no aporta proteínas ni otros nutrientes. Esta es una consideración importante, especialmente para los niños y adolescentes en crecimiento, y para los adultos mayores que tienen mayores necesidades de proteínas (Bauer et al. 2015).

La leche de coco, al igual que otras leches vegetales, no contiene lactosa, por lo que es adecuada para personas con intolerancia a la lactosa. Sin embargo, si la intolerancia a la lactosa es la única preocupación, la leche de vaca sin lactosa también está disponible en el mercado.

El coco no es considerado un alérgeno alimentario importante por la Administración de Drogas y Alimentos de los EE. UU. (FDA, por sus siglas en inglès), mientras que los lácteos son los primeros en la lista (FDA n.d.). Las personas con alergia a la proteína de la leche de vaca pueden consumir leche de coco de forma segura. Esto también es una ventaja sobre otras leches vegetales que también contienen alérgenos importantes (por ejemplo, soja y almendras). La leche de coco también es adecuada para su inclusión en una dieta vegana u ovovegetariana.

\section{¿Cuáles son los posibles riesgos de consumir leche de coco?}

Podría haber desventajas al consumir leche de coco. Esta leche tiene un alto contenido de grasas saturadas, en comparación con otras leches vegetales. En las pautas dietéticas para estadounidenses, se recomienda consumir menos del 10 por ciento de las calorías por día de grasas saturadas para reducir el riesgo de enfermedad cardiovascular (USDA 2015). Optar por una leche de origen vegetal con menor contenido de grasa, como leche de almendras, avena, arroz o anacardo, o elegir leche de vaca sin grasa, pueden ser mejores opciones para limitar la ingesta de grasas saturadas. 


\section{¿Es la leche de coco una opción adecuada para los niños?}

Para un crecimiento y desarrollo óptimos, los niños deben consumir suficiente calcio, vitamina $\mathrm{D}$ y proteínas. La leche de vaca es una fuente de los tres nutrientes, por lo que la leche de vaca ayuda a desarrollar huesos y dientes fuertes. Al igual que otras leches de origen vegetal, la leche de coco está fortificada con calcio. Es posible que nuestros cuerpos no absorban esta forma agregada de calcio tan fácilmente como el calcio natural (Bridges 2018, Singhal et al. 2017). Para los niños, que tienen entre 1 y 8 años de edad, una porción de leche de coco fortificada ( 1 taza) proporciona aproximadamente el 50\% del calcio y el $25 \%$ de la vitamina $\mathrm{D}$ que necesitan consumir en un día, similar a la leche de vaca (Vitoria 2017). Sin embargo, la leche de vaca puede proporcionar una parte significativa de las necesidades proteicas diarias de un niño (Vitoria 2017), mientras que la leche de coco no proporciona ninguna (Silk n.d.-b, Vitoria 2017). La leche de coco, como cualquier otra leche de origen vegetal, nunca debe administrarse a los bebés. Los niños mayores no deben beber leche de coco exclusivamente. Si las leches de origen vegetal se consideran una bebida para los niños, los padres y cuidadores deben consultar a su proveedor de atención médica para obtener orientación sobre la suplementación de proteínas, vitaminas y calorías en otras partes de la dieta (Vitoria 2017).

\section{Resumen}

La leche de coco es una alternativa a base de plantas fortificada con vitaminas y calcio, pero es una fuente de grasas saturadas. La leche de coco sin azúcar es una bebida baja en calorías. Debido a que carece de proteínas, la leche de coco no debe reemplazar la leche de vaca en la dieta de los niños.

\section{Referencias}

Bauer, Juergen M., and Rebecca Diekmann. 2015. "Protein and Older Persons." Clinics in Geriatric Medicine 31 (3): 327-338. https://doi.org/10.1016/j.cger.2015.04.002.

Bridges, Meagan. 2018. "Moo-Ove over, Cow's Milk: The Rise of Plant-Based Dairy Alternatives." Practical Gastroenterology 21. https://practicalgastro.com/wp-content/ uploads/2019/07/Moo-ove-Over-Cow-Milk-Rise-of-PlantBased-Dairy-Alternatives.pdf. [Accessed 10th August 2020].

Patil, Umesh, and Soottawat Benjakul. 2018. "Coconut Milk and Coconut Oil: Their Manufacture Associated with Protein Functionality." Journal of Food Science 83 (8): 2019-2027. https://doi.org/10.1111/1750-3841.14223.

Sethi, Swati, S. K. Tyagi, and Rahul K. Anurag. 2016. "Plant-Based Milk Alternatives an Emerging Segment of Functional Beverages: A Review." Journal of Food Science and Technology 53 (9): 3408-3423. https://doi.org/10.1007/ s13197-016-2328-3.

Silk. n.d.-a. “Original Coconutmilk." https://silk.com/ plant-based-products/coconutmilk/original-coconutmilk/. [Accessed 10th August 2020].

Silk. n.d.-b. "Unsweet Coconutmilk." https://silk.com/ plant-based-products/coconutmilk/unsweet-coconutmilk/. [Accessed 10th August 2020].

Singhal, Sarita, Robert D. Baker, and Susan S. Baker. 2017. "A Comparison of the Nutritional Value of Cow's Milk and Nondairy Beverages." Journal of Pediatric Gastroenterology and Nutrition 64 (5): 799-805. https://doi.org/10.1097/ mpg.0000000000001380.

United States Department of Agriculture (USDA). 2015. “Dietary Guidelines for Americans 2015-2020." http:// health.gov/dietaryguidelines/2015/guidelines/. [Accessed 10th August 2020].

United States Department of Agriculture (USDA). n.d. "Fooddata Central." https://fdc.nal.usda.gov/index.html. [Accessed 10th August 2020].

U.S. Food and Drug Administration (FDA). n.d. "Food Allergies: What You Need to Know.” https://www.fda. gov/Food/ResourcesForYou/Consumers/ucm079311.htm. [Accessed 10th August 2020].

Vitoria, Isidro. 2017. “The Nutritional Limitations of PlantBased Beverages in Infancy and Childhood." Nutrición Hospitalaria 34 (5): 1205-1214. https://www.redalyc.org/ pdf/3092/309253341026.pdf. [Accessed 10th August 2020]. 
Tabla 1. Perfil de nutrientes de la leche de coco sin azúcar en comparación con la leche de vaca sin grasa, baja en grasa y entera.

\begin{tabular}{|c|c|c|c|c|}
\hline & $\begin{array}{l}\text { Leche de coco sin } \\
\text { azúcar } \\
\text { (1 taza) }\end{array}$ & $\begin{array}{l}\text { Leche descremada } \\
\qquad(1 \text { taza) }\end{array}$ & $\begin{array}{l}\text { Leche semidescremada } \\
\qquad(1 \text { taza) }\end{array}$ & $\begin{array}{l}\text { Leche entera } \\
\text { (1 taza) }\end{array}$ \\
\hline Energía (Calorías) & 40 & 83 & 102 & 150 \\
\hline Proteína (g) & 0 & 8 & 8 & 8 \\
\hline Grasa total (g) & 4 & 0 & 2.4 & 8 \\
\hline Grasa saturada (g) & 3 & 0.1 & 1.5 & 4.5 \\
\hline Carbohidratos (g) & 1 & 12 & 12 & 12 \\
\hline Fibra (g) & 0 & 0 & 0 & 0 \\
\hline Azúcares totales (g) & 0 & 12 & 12 & 12 \\
\hline Vitamina A (mcg) & 180 & 149 & 142 & 112 \\
\hline Vitamina B12 (mcg) & 0.9 & 1 & 1 & 1 \\
\hline Vitamina D (mcg) & 2 & 3 & 3 & 3 \\
\hline Calcio (mg) & 460 & 298 & 305 & 276 \\
\hline Sodio (mg) & 45 & 102 & 107 & 105 \\
\hline Potasio (mg) & 310 & 381 & 366 & 322 \\
\hline
\end{tabular}

